\title{
Tay-Sachs disease: current perspectives from Australia
}

This article was published in the following Dove Press journal:

The Application of Clinical Genetics

21 January 2015

Number of times this article has been viewed

\author{
Raelia M Lew ${ }^{1,7}$ \\ Leslie Burnett $2,3,4$ \\ Anné L Proos ${ }^{2}$ \\ Martin B Delatycki ${ }^{5,6}$ \\ 'Department of Obstetrics and \\ Gynecology, QEII Research Institute \\ for Mothers and Infants, The \\ University of Sydney, Australia; ${ }^{2}$ NSW \\ Health Pathology North, Royal North \\ Shore Hospital, St Leonards, Australia; \\ ${ }^{3}$ SEALS, Prince of Wales Hospital, \\ Randwick, Australia; ${ }^{4}$ Sydney Medical \\ School-Northern, Royal North Shore \\ Hospital E25, University of Sydney, \\ Sydney, Australia; ${ }^{5}$ Department of \\ Clinical Genetics, Austin Health, \\ Heidelberg, Australia; 'Bruce Lefroy \\ Centre for Genetic Health Research, \\ Murdoch Childrens Research Institute, \\ Parkville, Australia; ' ${ }^{7}$ epartment \\ of Obstetrics and Gynaecology, \\ Dentistry and Health Sciences, \\ Faculty of Medicine, The University of \\ Melbourne, Melbourne, Australia
}

\begin{abstract}
Tay-Sachs disease (TSD) is a fatal, recessively inherited neurodegenerative condition of infancy and early childhood. Although rare in most other populations, the carrier frequency is one in 25 in Ashkenazi Jews. Australian high-school-based TSD preconception genetic screening programs aim to screen, educate, and optimize reproductive choice for participants. These programs have demonstrated high uptake, low psychological morbidity, and have been shown to result in fewer than expected Jewish TSD-affected births over 18 years of operation. The majority of Jewish individuals of reproductive age outside of the high school screening program setting in Australia have not accessed screening. Recent recommendations advocate supplementing the community high school screening programs with general practitioner- and obstetrician-led genetic screening of Ashkenazi Jewish individuals for TSD and other severe recessive diseases for which this group is at risk. Massively parallel DNA sequencing is expected to become the testing modality of choice over the coming years.
\end{abstract}

Keywords: Tay-Sachs disease, genetic screening, Australia

\section{Tay-Sachs disease}

Tay-Sachs disease (TSD), a fatal condition, is a neurodegenerative lysosomal sphingolipid storage disorder. TSD is caused by mutations of HEXA (MIM *606869, gene map locus 15q23-q24). The HEXA gene product was identified in 1969 as the $\alpha$-subunit of $\beta$-hexosaminidase enzyme (HEXA). The normal function of HEXA is to degrade GM2 gangliosides in central nervous system cell lysosomes. ${ }^{1,2}$ In TSD, neuronal accumulation of sphingolipid GM2 gangliosides results in progressive loss of central nervous system function. Most infants with TSD appear healthy at birth. After a period of normal development, affected individuals experience slow neurological decline and death in infancy (infantile TSD) or early childhood (intermediate TSD). A still milder form of TSD exists where individuals survive into adulthood. No cure or effective treatment to slow the progression of the disease is known. ${ }^{3}$ TSD has autosomal recessive inheritance, with TSD carriers being unaffected. In the case of carrier couples, $25 \%$ of pregnancies will be affected by TSD. TSD is a rare disease, with an incidence of one in 320,000 births in general populations (carrier frequency one in 250). The specific populations at a higher risk of TSD are: Ashkenazi Jewish (AJ), French Canadian, Irish, Pennsylvania Dutch, and Cajun communities. All populations exhibit specific $H E X A$ founder mutations at high allelic frequencies. ${ }^{4}$

\section{TSD screening initiatives}

TSD incidence in unscreened Jewish populations is one in 3,900 births. ${ }^{5}$ The first TSD carrier screening program was introduced in the USA in 1971, representing a precedent 
for population genetic screening for inherited diseases. ${ }^{6} \mathrm{By}$ the year 2000, over 51,000 TSD carriers, including more than 1,400 at-risk couples, had been identified via TSD screening programs around the world. ${ }^{7}$ Internationally, screening has reduced the incidence of Ashkenazi Jews with TSD-affected children by more than $90 \% .^{5}$

\section{TSD and the Australian AJ population}

The Australian Jewish community mainly reside in Melbourne and Sydney ${ }^{8}$ and was estimated to number 97,300 in the 2011 Australian Bureau of Statistics Census of Population and Housing. ${ }^{9}$ The majority of Australian Jews have AJ heritage. ${ }^{10}$ TSD carrier frequency is approximately one in $25^{11}$ in Australian individuals of AJ descent. ${ }^{11}$

\section{Australian TSD genetic screening programs}

Over $70 \%$ of Jewish adolescents in Melbourne and 50\% in Sydney attend Jewish high schools that access TSD screening programs (Eckstein, unpublished data, 2006). Although the at-risk population was primarily residing in Melbourne and Sydney, the testing laboratories were located remotely in different states of Australia: at the Chemical Pathology Department, Royal Brisbane Hospital (now part of Pathology Queensland) and at the Chemical Pathology Department, Adelaide Women's and Children's Hospital (now part of SA Pathology). All cases of TSD diagnosed in Australia prior to the commencement of TSD carrier screening in the Australian AJ community underwent confirmatory biochemical and/or genetic testing at one or more of these laboratory sites. Prior to 1993, TSD testing and family cascade carrier screening in Australia was available through medical consultation only at these two laboratories. In 1993, a 2-year pilot study commenced in Sydney ${ }^{12}$ for what would develop into Australia's first TSD screening program for Jewish high school students. ${ }^{13}$ With the introduction of community screening, diagnostic TSD testing was then carried out in two additional Australian laboratory sites: in Sydney (initially in the Clinical Chemistry Department, Institute of Clinical Pathology and Medical Research, Westmead Hospital; subsequently relocating in 1997 to the Laboratory and Community Genetics Department, Pacific Laboratory Medicine Services [PaLMS, now a part of NSW Health Pathology North], Royal North Shore Hospital) and to Melbourne (Victorian Clinical Genetics Service).

\section{Elements of successful international TSD screening programs were adapted for an Australian community}

Educational campaigns focusing on the medical community, Jewish community, and religious leaders, and training of volunteers were undertaken to ensure dialogue occurred and the eventual model of TSD screening designed was adapted to community needs, expectations, and resources. ${ }^{14,15}$ Australian TSD screening programs adhere to international ethical standards with regard to individual privacy and patient autonomy. ${ }^{16}$ Genetic screening within programs is fully informed and voluntary. Genetic screening programs targeting senior high school students have been associated with high uptake, both internationally and in Australia. ${ }^{13,17,18}$

\section{TSD screening in Sydney}

Following a 2-year pilot study (1993-1994), ${ }^{12}$ the Australasian Community Genetics Program (Laboratory and Community Genetics Department, Pacific Laboratory Medicine Services [PaLMS, NSW Health Pathology North], Royal North Shore Hospital [RNSH], Sydney) began as the first Australian TSD screening program in 1995, targeting 15-17-year-old students attending Jewish high schools. ${ }^{13}$ Originally based at Westmead Hospital, the community and administrative headquarters of the program were relocated to the Wolper Jewish Hospital (situated geographically close to the heart of Sydney's Jewish community), and the laboratory service subsequently moved to the Laboratory and Community Genetics Department, Pacific Laboratory Medicine Services (PaLMS, NSW Health Pathology North]. A further possible relocation, to be similarly geographically closer to the Jewish community, is currently under discussion. Testing is free of charge to participating students, with costs being funded partially by philanthropic support from the Jewish community, and the balance from NSW Health. Parental written consent for participation in screening is required for students aged less than 16 years. Young adult outreach preconception genetic screening for TSD, and now also other recessive diseases common in the AJ community (cystic fibrosis, mucolipidosis type IV, Fanconi anemia, familial dysautonomia, Canavan disease, Bloom syndrome), is offered annually. ${ }^{13}$ As part of the high school program, an initial compulsory education session is facilitated for all students offered testing several days prior to voluntary sample collection, currently led by a qualified 
genetic counselor. Students' retention of knowledge following participation in the pre-test education session has been found to be high. ${ }^{13}$ Uptake of voluntary testing is $94 \%$. Students who decline testing are provided with written information regarding access to testing in the future. Three options (A, B, and D) are offered to students regarding access to their test results. Scheme A is analogous to the Dor Yeshorim model, ${ }^{19}$ where carrier status is withheld by the testing laboratory. Results may, at a nominated later date, be interpreted in the context of a partner's screening result and reported as a risk or possibility of TSD-affected pregnancy. In scheme B, results of the screening are made available to students immediately with genetic counseling. In Scheme D, students nominate to have a DNA sample taken and analyzed but reporting is deferred until a later time of the student's choosing. ${ }^{20}$ The vast majority of students currently choose scheme B (direct disclosure). Students who enter in Scheme D can, at a later date, nominate to change to Scheme A or B.

The emotional impact of testing has been shown to be acceptable to students, generating low levels of concern in adolescents found to be carriers. ${ }^{13}$ Specimen collection was initially by venepuncture (1995-2004) and subsequently by mouthwash sampling (2004-2014). Testing was initially by biochemical methods with DNA testing of confirmed carriers (1995-2004). Today DNA-only initial testing is standard, with confirmation of carrier status by a second DNA method (1995-2014). ${ }^{21}$ Genetic counseling is routinely offered to all students found to be genetic carriers, and is also available on request to all students.

\section{TSD screening in Melbourne}

In 1998, a TSD carrier screening program, based on the Sydney model and conducted by Genetic Health Services Victoria until 2009, and subsequently by Austin Health, was established in Jewish high schools in Melbourne. ${ }^{22}$ Testing incurred a cost of \$40 AUD per student tested in 1998, but was fully funded thereafter by Melbourne Jewish Community philanthropic organizations. The program is voluntary and is available to students aged $15-18$ years. Initially, screening was for TSD only but has since expanded to include a panel of recessive conditions at increased frequency in Jewish populations. Pre-test education is provided, currently led by a qualified genetic counselor. Uptake increased from 67\% (1998-2001) to 96\% (2003) following the change of sample collection method from venepuncture to cheek-brush sampling. ${ }^{23}$ Informed consent is obtained by a screening program team member in a one-to-one interview prior to students providing a DNA sample. ${ }^{18}$ Students found to be carriers are contacted by phone by a genetic counselor and offered an outpatient genetic counseling appointment. Additionally, carriers receive a copy of their result and an explanatory letter by mail to facilitate cascade screening of family members. A copy of their result and an explanatory letter is mailed to non-carrier students. ${ }^{18,23}$

A recent study was undertaken to assess the long-term (5- to 11-year) outcomes of screening within the Melbourne program. ${ }^{24}$ Validated questionnaires were sent to all carriers and two non-carriers per carrier screened between 1999 and 2005 . The questionnaire was completed by $34.8 \%$ of carriers and $21.7 \%$ of non-carriers. The percentage of participants who retained good knowledge of TSD with no significant difference in knowledge between carriers and non-carriers was $82 \%$, and $83 \%$ of respondents were happy with the timing and high school setting of the screening and thought that this approach should continue. There was no significant difference in negative psychological consequences between carriers and non-carriers as assessed by validated anxiety and decision regret scales. Screened individuals were supportive of the program.

\section{The Dor Yeshorim screening program - an alternative approach in ultraorthodox Jewish communities}

The Dor Yeshorim screening program was established in 1983 to provide access to TSD screening to the ultra-orthodox Jewish community in the USA in a format culturally acceptable to this demographic. A branch of this program has been operating in Israel since 1986. ${ }^{19}$ The program has since been expanded to test for other significant recessive conditions at higher than background frequencies in Jewish populations, and can be accessed by request by ultra-orthodox $\mathrm{AJ}$ individuals around the world, including Australians. This program differs from mainstream genetic screening programs in several ways. Individual genetic results are not disclosed; instead, the point of interest is a potential couple's genetic compatibility. Non-compatible carrier couples not introduced as a suitable match. This mode of screening is designed to prevent disease and to avoid the stigma that may be associated with the knowledge of individual carrier status within relatively small ultra-orthodox communities. 


\section{Pros and cons of TSD genetic screening in an adolescent population}

The ideal setting in which to screen for TSD is an informed adult couple planning a future pregnancy. ${ }^{26}$ Unfortunately, this demographic often do not access preconception testing for many reasons, including low knowledge of carrier risk, low knowledge of screening options, low motivation, cost of testing, or unplanned pregnancy. ${ }^{27,28} \mathrm{~A}$ factor that has most successfully increased uptake of preconception genetic screening for TSD internationally has been the implementation of screening programs that target an adolescent population. ${ }^{15}$ Screening of senior high school students, as occurs in Australian AJ TSD genetic screening programs, captures a large proportion of the target population in an environment where both pre-test education and testing can be facilitated with relative ease. Senior high school students are mature minors, and are generally able to understand the implications of testing and provide informed consent. ${ }^{29,30}$ Students educated prior to testing and then screened for TSD in a high school setting have been found to retain more information at the time of testing and 3-6 years following testing than adults screened in other settings..$^{13,17,22,23}$ In order to be optimally relevant, TSD carrier screening must occur in a window before conception, with all reproductive options accessible, allowing couples to make informed choices in planning their family. ${ }^{31}$ Carrier testing in an adolescent population addresses the issue of TSD screening prior to pregnancy planning, thus allowing future informed access to a full range of reproductive options for at-risk families. ${ }^{32}$

\section{TSD screening and diagnosis: assays and strategies HEXA enzyme assay}

In 1971 an assay for HEXA protein was developed, allowing the possibility of TSD antenatal testing and carrier screening. ${ }^{33}$ HEXA enzyme testing remains the accepted gold standard for TSD screening and diagnosis. HEXA testing has $98 \%$ sensitivity, and can be used in pan-ethnic populations and in the presence of rare and/or founder mutations. ${ }^{34} \mathrm{TSD}$ carriers have enzyme activity $<52 \%$ compared to non-carriers where enzyme activity is $>60 \% .{ }^{34}$ However, HEXA enzyme testing has several pitfalls. Testing requires venepuncture, which can lead to lower acceptance and participation rates in community screening. Technical limitations in overlapping reference intervals mean that there is an inconclusive range of enzyme activity (52\% to $60 \%$ ) in which it is difficult to distinguish TSD carriers from non-carriers. ${ }^{35}$ Rarely, false negative and false positive results can occur (eg, B1 allele ${ }^{36,37}$ and pseudodeficiency alleles, ${ }^{38}$ respectively). Medications including oral contraceptives may affect detected enzyme levels. ${ }^{39}$

\section{Traditional HEXA DNA testing}

DNA molecular testing for a panel of known mutations is highly sensitive and specific when applied to an appropriately selected population.

In AJ populations, several mutant $H E X A$ alleles have been demonstrated ${ }^{40}$ Ninety-six percent of Jewish TSD carriers have one of three common mutations. ${ }^{6,7}$ c.1278insTATC, the most common mutation in AJ populations, is a frameshift mutation due to a four-base-pair insertion in exon 11, introducing a premature stop codon and causing protein truncation; ${ }^{41}$ c. $1421+1 \mathrm{G}>\mathrm{C}$, the second most common mutation in AJ populations, is a $\mathrm{G} \rightarrow \mathrm{C}$ transversion in the donor splice site of intron $12,{ }^{40,42,43}$ and p.Gly269Ser is a rarer missense mutation. ${ }^{44}$

In $\mathrm{AJ}$ populations it has been shown that DNA mutation testing is the most accurate and cost-effective assay for TSD population genetic screening. ${ }^{5,45}$ DNA testing of mouthwash/ cheek brush samples improves participation rates compared with blood sampling required for biochemical testing. ${ }^{23}$ Successful DNA testing of hair root specimens offers a sample amenable to extreme ease of transport, and potential use for outreach screening. ${ }^{46}$

\section{Massively parallel DNA sequencing}

Massively parallel DNA sequencing (MPS) has been shown to be superior to HEXA enzyme-based screening and traditional DNA genotyping methodologies in research settings. ${ }^{47}$ MPS-based genetic screening can be applied to TSD, but also has the potential to simultaneously offer screening for high numbers of targeted genetic conditions in non-selected populations ${ }^{48}$ The costs of MPS technology are reducing, but remain significant. Another limiting factor in the application of MPS-based genetic screening strategies is the unresolved issue of the interpretation and reporting of incidental findings and variants of unknown significance..$^{47,49}$ The Sydney AJ Community Genetic Screening program is currently conducting a pilot study using an expanded MPS panel for up to 26 recessive conditions as part of AJ preconception genetic screening (L Burnett and A Proos, unpublished data, 2014). Ioannou et al found that increasing the number of conditions included in the Melbourne AJ Community Genetic Screening program from TSD alone to seven conditions 
resulted in a decrease in knowledge and increase in predicted negative feelings if found to be a carrier of one or more of the conditions. ${ }^{18}$ Other studies are underway assessing the psychological impact of an expanded screening menu incorporating seven recessive conditions. Further research will be needed to ensure that MPS screening is conducted in a way that maintains ethical principles of autonomy, beneficence, non-maleficence, and justice. Information derived from MPS sequencing may have additional longitudinal benefits for patients as data collected may be re-interrogated in the future. ${ }^{50}$

\section{Cost of testing}

The costs of enzyme-, DNA-, and MPS-based assays are all similar in the range of $\$ 100$ to $\$ 500$ AUD (L Burnett and A Proos, unpublished data, 2014).

Following TSD enzyme testing (serum enzyme activity \pm leukocyte enzyme activity), DNA testing may also be required to address some of the technical limitations described above.

In addition to reagent costs, MPS sequencing will have supplementary costs for bioinformatics interpretation and reporting, which are yet to be formally assessed.

\section{Models of screening}

Screening models to identify carrier couples include one-step models where both partners undertake screening immediately and two-step models where partners are screened sequentially. Under most circumstances, two-step carrier screening is the most cost-effective option for at-risk couples. In the two-step screening model, the second partner is tested only where the first partner was confirmed by screening to be a TSD carrier. One-step carrier screening is appropriate in settings where the results of screening are urgently required (eg, during a pregnancy). The Dor-Yeshorim model also utilizes one-step carrier screening. ${ }^{51}$

\section{Reproductive options for carrier couples}

Options to avoid TSD-affected pregnancies in a couple at risk include using assisted reproductive technologies, including in vitro fertilisation/intracytoplasmic sperm injection with preimplantation genetic diagnosis or use of a donor gamete to achieve healthy embryos. In spontaneous pregnancies, antenatal diagnosis can be availed with the possibility of selective termination of TSD-affected pregnancies. Invasive methods of fetal diagnostic testing include chorion villus sampling and amniocentesis. Both these methods carry a test-related risk of miscarriage $(0.5 \%$ to $1 \%)$ and are offered from the late first trimester of pregnancy onward..$^{52}$ Detection of free fetal DNA in a maternal blood sample offers a promising non-invasive option for future fetal diagnosis that could potentially be offered from the very early first trimester of pregnancy onward. ${ }^{53}$ Other options for couples at risk include the use of donor gametes, adoption, making a decision to remain childless, leaving the pregnancy outcome to fate, or (as with the Dor Yeshorim program) avoiding the issue by having chosen a partner who was already known not to be a potential "at-risk" couple partnership.

\section{Success of Australian TSD screening programs}

Measures of the success of a genetic screening program include uptake within the target population, percentage of the target population offered access to screening, the level of informed consent among individuals screened, the reduction of target disease incidence over time through the uptake of assisted reproductive technologies, and selective pregnancy termination and economic outcomes. ${ }^{54}$

In world Jewish communities, TSD carrier screening programs have reduced the births of infants with TSD by $>90 \%$. ${ }^{6,17,18}$ Prior to $1970,85 \%$ of TSD affected infants were born to Jewish parents. TSD frequency in non-Jewish populations has, during the same time-frame, remained stagnant. Currently the majority of TSD affected infants are born to non-Jewish parents. ${ }^{6,55}$ Studies of the allele frequencies of several genes in the Australian Jewish population in Sydney including $H E X A, B R C A 1, B R C A 2$, and $A P C$ indicate the Australian Jewish population is not statistically different from Jewish populations in Israel, USA, and Canada and is therefore comparable to international Jewish populations with regard to the burden of genetic diseases. ${ }^{11,56}$ The impact of wide reaching TSD screening programs targeting Jewish communities in Australia can, in the long-term, be expected to have similar implications for reducing TSD incidence as international programs have demonstrated. In 2011, a comprehensive and consecutive audit of all TSD cases diagnosed in Australia from 1995 onward was conducted. ${ }^{55}$ Fewer than expected numbers of Jewish TSD cases were noted within the audit, corresponding to the period where Jewish community TSD preconception genetic screening programs were operating in Sydney and Melbourne. The majority of TSD cases were found to have occurred in non-Jewish Australian families. No AJ TSD preconception genetic screening program participant over the past 18 years has gone on to have a TSD-affected child. Two cases of TSD have occurred in 
Australia since 1995 affecting two different AJ families. None of the four AJ parents of the two AJ TSD-affected infants had previously undergone TSD genetic screening.

A major pitfall in Australian AJ genetic screening is low participation rates outside of adolescent-focused high school screening programs, with fewer than 50\% of Australian Jewish individuals of reproductive age having accessed these programs (Eckstein, unpublished data, 2006). ${ }^{51}$ This residual target population relies on personal request or health care clinician referral for TSD screening. Barriers to clinician referral include costs, time constraints, and availability of supporting services, as well as patient and clinician education. ${ }^{57}$ In Israel, clinicians are instructed to offer access to genetic screening for TSD to all AJ women of reproductive age, ideally prior to pregnancy, but also during pregnancy. The Israeli system is an example of how clinicians can effectively facilitate preconception genetic screening strategies to prevent the targeted condition/s. ${ }^{31,58}$ The Human Genetics Society of Australasia is currently formulating guidelines to assist Australian healthcare providers in implementing this practice (I Stechiwskyj, unpublished data, 2014).

As MPS-facilitated genetic screening technology evolves and costs reduce over time, it is highly likely that genetic screening for a large range of serious rare genetic diseases will become routine in antenatal care in pan-ethnic populations. As has been demonstrated with TSD in AJ communities that have been intensively studied, genetic screening can be expected to have a net health benefit to families and communities. Further research is needed to understand how expanded genetic screening for a greater number of conditions will impact screened individuals psycho-socially to optimize the potential nethealth benefit of screening.

\section{Disclosure}

The authors report no conflicts of interest in this work.

\section{References}

1. Okada S, O'Brien JS. Tay-Sachs disease: generalized absence of a beta-D-N-acetylhexosaminidase component. Science. 1969;165(3894): 698-700.

2. Sandhoff K. Variation of beta-N-acetylhexosaminidase-pattern in Tay-Sachs disease. FEBS Lett. 1969;4(4):351-354

3. Gravel RA, Clarke JTR, Kaback MM, et al. The GM2 gangliosidoses. In: Scriver CR, Beaudet AL, Sly WS, Valle D, editors. The Metabolic and Molecular Basis of Inherited Disease. 7th ed. New York: McGraw-Hill; 1995:2839-2879.

4. Vallance H, Ford J. Carrier testing for autosomal-recessive disorders. Crit Rev Clin Lab Sci. 2003;40(4):473-497.

5. Triggs-Raine BL, Feigenbaum AS, Natowicz M, et al. Screening for carriers of Tay-Sachs disease among Ashkenazi Jews. A comparison of DNA-based and enzyme-based tests. New Engl J Med. 1990;323(1):6-12.
6. Kaback M, Lim-Steele J, Dabholkar D, Brown D, Levy N, Zeiger K. Tay-Sachs disease - carrier screening, prenatal diagnosis, and the molecular era. An international perspective, 1970 to 1993. The International TSD Data Collection Network. JAMA. 1993;270(19): 2307-2315.

7. Kaback MM. Population-based genetic screening for reproductive counseling: the Tay-Sachs disease model. Eur J Pediatr. 2000; 159 Suppl 3:S192-S195.

8. Rubinstein WD. Judaism in Australia. Australian Govt Pub Service; 1995.

9. Statistics ABo. Reflecting a Nation: Stories from the 2011 Census. Catalogue 2071.0 2012-2013.

10. Rutland SD. The Jews in Australia. Port Melbourne: Cambridge University Press; 2005.

11. Lew R, Burnett L, Proos A. Tay-Sachs disease preconception screening in Australia: self-knowledge of being an Ashkenazi Jew predicts carrier state better than does ancestral origin, although there is an increased risk for c. $1421+1 \mathrm{G}>\mathrm{C}$ mutation in individuals with South African heritage. J Community Genet. 2011;2(4):201-209.

12. Burnett L, Proos AL, Chesher D, et al. The Tay-Sachs disease prevention program in Australia: Sydney pilot study. Med J Aust. 1995;163(6):298-300.

13. Barlow-Stewart K, Burnett L, Proos A, et al. A genetic screening programme for Tay-Sachs disease and cystic fibrosis for Australian Jewish high school students. J Med Genet. 2003;40(4):e45.

14. Kaback MM. Screening and prevention in Tay-Sachs disease: origins, update, and impact. Adv Genet. 2001;44:253-265.

15. Ross LF. Heterozygote carrier testing in high schools abroad: what are the lessons for the US? J Law Med Ethics. 2006;34(4):753-764.

16. Godard B, ten Kate L, Evers-Kiebooms G, Aymé S. Population genetic screening programmes: principles, techniques, practices, and policies. Eur J Hum Genet. 2003;11 Suppl 2:S49-S87.

17. Mitchell JJ, Capua A, Clow C, Scriver CR. Twenty-year outcome analysis of genetic screening programs for Tay-Sachs and beta-thalassemia disease carriers in high schools. Am J Hum Genet. 1996;59(4): 793-798.

18. Ioannou L, Massie J, Lewis S, et al. Evaluation of a multi-disease carrier screening programme in Ashkenazi Jewish high schools. Clin Genet. 2010;78(1):21-31.

19. Broide E, Zeigler M, Eckstein J, Bach G. Screening for carriers of Tay-Sachs disease in the ultraorthodox Ashkenazi Jewish community in Israel. Am J Med Genet. 1993;47(2):213-215.

20. Burnett L, Proos AL, Barlow-Stewart K, Aizenberg H. Evaluation of deferred selection of result reporting strategies in community genetic screening for autosomal recessive disorders. Twin Res Hum Genet. 2013;16(4):904.

21. Warren E, Anderson R, Proos AL, Burnett LB, Barlow-Stewart K, Hall J, Cost-effectiveness of a school-based Tay-Sachs and cystic fibrosis genetic carrier screening program. Genet Med. 2005;7(7):484-494.

22. Gason AA, Sheffield E, Bankier A, et al. Evaluation of a Tay-Sachs disease screening program. Clin Genet. 2003;63(5):386-392.

23. Gason AA, Metcalfe SA, Delatycki MB, et al. Tay Sachs disease carrier screening in schools: educational alternatives and cheekbrush sampling. Genet Med. 2005;7(9):626-632.

24. Curd H, Lewis S, Macciocca I, et al. High school Tay-Sachs disease carrier screening: 5 to 11-year follow-up. J Community Genet. 2014;5(2): 139-146.

25. Ekstein J, Katzenstein H. The Dor Yeshorim story: community-based carrier screening for Tay-Sachs disease. Adv Genet. 2001;44:297-310.

26. Frumkin A, Zlotogora J. Genetic screening for reproductive purposes at school: is it a good strategy? Am J Med Genet A. 2008;146A(2): 264-269.

27. Black KI, Gupta S, Rassi A, Kubba A. Why do women experience untimed pregnancies? A review of contraceptive failure rates. Best Pract Res Clin Obstet Gynaecol. 2010;24(4):443-455.

28. Stark Z, Massie J, McClaren B, et al. Current practice and attitudes of Australian obstetricians toward population-based carrier screening for inherited conditions. Twin Res Hum Genet. 2013;16(2):601-607. 
29. Gillick v West Norfolk \& Wisbech Area Health Authority [1985] UKHL 7 (17 October 1985) [webpage on the Internet]. England: British and Irish Legal Information Institute (BAILII); 1985. Available from: http://www.bailii.org/uk/cases/UKHL/1985/7.html. Accessed October 8, 2014

30. Department of Health and Community Services v JWB and SMB. 1992.

31. Zlotogora J. Population programs for the detection of couples at risk for severe monogenic genetic diseases. Hum Genet. 2009;126(2): 247-253.

32. Genetics ACo ACOG Committee Opinion No 442: Preconception and prenatal carrier screening for genetic diseases in individuals of Eastern European Jewish descent. Obstet Gynecol. 2009;114(4):950-953.

33. Lowden JA, Skomorowski MA, Henderson F, Kaback M. Automated assay of hexosaminidases in serum. Clin Chem. 1973;19(12): 1345-1349.

34. Monaghan KG, Feldman GL, Palomaki GE, Spector EB. Ashkenazi Jewish Reproductive Screening Working Group, Molecular Subcommittee of the ACMG Laboratory Quality Assurance Committee. Technical standards and guidelines for reproductive screening in the Ashkenazi Jewish population. Genet Med. 2008;10(1):57-72.

35. Schneider A, Nakagawa S, Keep R, et al. Population-based Tay-Sachs screening among Ashkenazi Jewish young adults in the 21st century: Hexosaminidase A enzyme assay is essential for accurate testing. $\mathrm{Am}$ J Med Genet A. 2009;149A(11):2444-2447.

36. Kytzia HJ, Sandhoff K. Evidence for two different active sites on human beta-hexosaminidase A. Interaction of GM2 activator protein with beta-hexosaminidase A. J Biol Chem. 1985;260(12): 7568-7572.

37. Fernandes M, Kaplan F, Natowicz M, et al. A new Tay-Sachs disease B1 allele in exon 7 in two compound heterozygotes each with a second novel mutation. Hum Mol Genet. 1992;1(9):759-761.

38. Triggs-Raine BL, Mules EH, Kaback MM, et al. A pseudodeficiency allele common in non-Jewish Tay-Sachs carriers: implications for carrier screening. Am J Hum Genet. 1992;51(4):793-801.

39. D'Souza G, McCann CL, Hedrick J, et al. Tay-Sachs disease carrier screening: a 21-year experience. Genet Test. 2000;4(3):257-263.

40. Arpaia E, Dumbrille-Ross A, Maler T, et al. Identification of an altered splice site in Ashkenazi Tay-Sachs disease. Nature. 1988, 333(6168):85-86.

41. Myerowitz R, Costigan FC. The major defect in Ashkenazi Jews with Tay-Sachs disease is an insertion in the gene for the alpha-chain of beta-hexosaminidase. J Biol Chem. 1988;263(35):18587-18589.

42. Myerowitz R. Splice junction mutation in some Ashkenazi Jews with Tay-Sachs disease: evidence against a single defect within this ethnic group. Proc Natl Acad Sci U S A. 1988;85(11):3955-3959.

43. Ohno K, Suzuki K. A splicing defect due to an exon-intron junctional mutation results in abnormal beta-hexosaminidase alpha chain mRNAs in Ashkenazi Jewish patients with Tay-Sachs disease. Biochem Biophys Res Commun. 1988;153(1):463-469.
44. Navon R, Proia RL. The mutations in Ashkenazi Jews with adult GM2 gangliosidosis, the adult form of Tay-Sachs disease. Science. 1989;243(4897):1471-1474.

45. Bach G, Tomczak J, Risch N, Ekstein J. Tay-Sachs screening in the Jewish Ashkenazi population: DNA testing is the preferred procedure. Am J Med Genet. 2001;99(1):70-75.

46. Brillante R, Yang V, Proos A, Burnett L. PCR analysis of hair root specimens to detect Tay-Sachs disease carriers in Ashkenazi Jews. Clin Chem. 1995;41(2):321-322.

47. Hoffman JD, Greger V, Strovel ET, et al. Next-generation DNA sequencing of HEXA: a step in the right direction for carrier screening. Mol Genet Genomic Med. 2013;1(4):260-268.

48. Bell CJ, Dinwiddie DL, Miller NA, et al. Carrier testing for severe childhood recessive diseases by next-generation sequencing. Sci Transl Med. 2011;3(65):65ra64.

49. Green RC, Berg JS, Grody WW, et al. ACMG recommendations for reporting of incidental findings in clinical exome and genome sequencing. Genet Med. 2013;15(7):565-574.

50. Biesecker LG. Opportunities and challenges for the integration of massively parallel genomic sequencing into clinical practice: lessons from the ClinSeq project. Genet Med. 2012;14(4):393-398.

51. Lew RM, Burnett L, Proos AL, et al. Ashkenazi Jewish population screening for Tay-Sachs disease: The International and Australian experience. J Paediatr Child Health. Epub June 13, 2014.

52. Sekizawa A, Purwosunu Y, Matsuoka R, et al. Recent advances in noninvasive prenatal DNA diagnosis through analysis of maternal blood. $J$ Obstet Gynaecol Res. 2007;33(6):747-764.

53. Hui L, Bianchi DW. Recent advances in the prenatal interrogation of the human fetal genome. Trends Genet. 2013;29(2):84-91.

54. Delatycki MB. Population screening for reproductive risk for single gene disorders in Australia: now and the future. Twin Res Hum Genet. 2008;11(4):422-430.

55. Lew RM, Proos AL, Burnett L, Delatycki M, Bankier A, Fietz MJ. Tay Sachs disease in Australia: reduced disease incidence despite stable carrier frequency in Australian Jews. Medical J Aust. 2012;197(11): 652-654.

56. Bahar AY, Taylor PJ, Andrews L, et al. The frequency of founder mutations in the BRCA1, BRCA2, and APC genes in Australian Ashkenazi Jews: implications for the generality of US population data. Cancer. 2001;92(2):440-445.

57. Stark Z, Massie J, McClaren B, et al. Current practice and attitudes of Australian obstetricians toward population-based carrier screening for inherited conditions. Twin Res Hum Genet. 2013;16(2):601-607.

58. Chemke J, Zlotogora J. Genetic services in Israel. Eur J Hum Genet. 1997;5 Suppl 2:105-111.
The Application of Clinical Genetics

\section{Publish your work in this journal}

The Application of Clinical Genetics is an international, peer-reviewed open access journal that welcomes laboratory and clinical findings in the field of human genetics. Specific topics include: Population genetics; Functional genetics; Natural history of genetic disease; Management of genetic disease; Mechanisms of genetic disease; Counseling and ethical

\section{Dovepress}

issues; Animal models; Pharmacogenetics; Prenatal diagnosis; Dysmorphology. The manuscript management system is completely online and includes a very quick and fair peer-review system, which is all easy to use. Visit http://www.dovepress.com/testimonials.php to read real quotes from published authors 